\title{
A TECNOLOGIA ASSISTIVA NA ESPECIFICIDADE VISUAL
}

Edilany Mendonça Vales

Geógrafa. Docente substituta da Universidade Federal do AmapáUNIFAP. Licenciada em Geografia. Especialista em Educação Especial e Inclusiva. Mestranda no Programa de Pós-graduação/ Mestrado em Desenvolvimento Regional da UNIFAP. E-mail: edilany.mvales@gmail.com

\section{RESUMO}

A modernidade tecnológica avançou chegando à educação, inclusive possibilitando ao ensino novas opções de recursos de acessibilidade para o atendimento aos alunos com especificidades visuais. $\mathrm{O}$ presente trabalho trata da necessidade emergente da inclusão social desses alunos, através de ferramentas tecnológicas e de ações que atenda suas necessidades no âmbito educacional, partindo de um novo pensar acerca do desenvolvimento e aprendizagem.

PALAVRAS-CHAVE: Inclusão. Tecnologia. Cego.

\section{ASSISTANT TECHNOLOGY IN VISUAL SPECIFICITY}

\begin{abstract}
Technological modernity has advanced to education, including allowing teaching new options of accessibility features to serve students with visual specificities. This paper addresses the emerging need for social inclusion of these students through technological tools and actions that meet their educational needs, starting from a new thinking about development and learning.
\end{abstract}

KEYWORDS: Inclusion. Technology. Blind. 


\section{INTRODUÇÃO}

Qualquer estudo que pretende se aprofundar sobre a chegada das novas tecnologias na educação deve ir além da observação do paradigma do uso do computador como mera peça de adorno ou referência de status, a questão da informática na educação vai mais além da discussão dos softwares, mais sim, nas propostas de mudanças operadas por eles na prática pedagógica. O crescimento da informática exerce grande impacto na vida da pessoa com especificidade visual, vários setores como o produtivo, o industrial, o financeiro, da pesquisa científica, das comunicações e outros, já estão informatizados.

Com a criação dos leitores de telas, instalados nos computadores, é o momento e a vez do Setor Educacional dar o seu salto olímpico e ingressar no futuro digital, apesar de investimentos feitos no setor educacional pela esfera governamental e das qualidades inerentes ao computador, a disseminação do seu uso nas escolas está muito aquém da esperada. Se por um lado suscita a curiosidade, o fascínio e o interesse do aluno, por uma educação informatizada, por outro lado apavoram o professor mantido nos moldes tradicionais de ensino, com metodologias e recursos extrapolados, durante sua trajetória profissional.

Diante desse contexto, delimitamos um tema para estudo, ou seja, uma reflexão sobre o uso do computador nas salas multifuncionais, como auxiliadores do processo de aprendizagem, bem como, as contribuições que os softwares oferecem a acessibilidade educacional, a criação e evolução dos conhecimentos para o cego, isso pode representar o crescimento de

oportunidade de autonomia e de inclusão sócio educacional, podendo ainda significar a continuidade a um processo de exclusão caso não seja oferecido o devido acesso a essas tecnologias.

\section{A PESSOA CEGA NO PROCESSO HISTÓRICO}

Nos primórdios da humanidade as crianças que nasciam cegas ou as pessoas que ficavam cegas no decorres da vida eram freqüentemente abandonadas e eliminadas, como se elas não merecesse ter direito a vida. As crenças daquela sociedade levavam as pessoas a acreditarem que elas eram possuídas por espíritos malignos e conviver com estas pessoas era o mesmo que conviver com os demônios, segundo ( Mecloy 1974), a cegueira era considerada um castigo infligido pelos deuses, e a pessoa cega levava em si mesma o estigma do pecado cometido por ele, por seus pais, seus avós ou por algum membro da tribo.

Em Atenas, na Grécia Antiga, os recém nascidos cegos eram colocados em uma vasilha Complexitas - Rev. Fil. Tem., Belém, v. 4, n. 2 , p. 27-32, jul./dec. 2019 - ISSN: 2525-4154 
de argila e abandonados. Em Esparta, onde os cidadãos pertencem ao Estado, os pais tinham o dever de apresentar seus filhos errante aos magistrados em praça pública, as crianças cegas eram consideradas subumanas, o que legitimava sua eliminação ou abandono, atitude perfeitamente coerente com as idéias atléticas e clássicas com a organização sociocultural da época. Em Roma, o procedimento mais comum também era a eliminação.

Em 1819, esteve no Instituto Nacional dos Jovens Cegos, em Paris, o oficial do exército francês Charles Barbier com uma sugestão que julgava ser bastante útil aos professores e alunos cegos, tratava-se de um processo de escrita, por ele idealizado, próprio para a transmissão de mensagens no campo de batalha à noite, sem utilização de luz para não atrair a atenção dos inimigos.

Em 1829, um jovem cego francês, Louis Braille (1809-1852), estudante daquele Instituto, fez uma adaptação do código militar de comunicação noturna, criado por Barbier, para as necessidades dos cegos, de início a adaptação foi denominada de sonografia e, mais tarde, de Braille.

\subsection{DESAFIOS DA EDUCAÇÃO INCLUSIVA MEDIADA PELA TECNOLOGIA}

A Tecnologia de Informação e de Comunicação (TIC) é utilizada como Tecnologia Assistiva, conceito que designa toda e qualquer ferramenta ou recurso utilizado com a finalidade de proporcionar uma maior independência e autonomia a pessoa com especificidade visual.

A aprendizagem é um processo, através do qual o sujeito não só adquire conhecimentos, conteúdos e informações, mas adquirem e assimilam novos padrões de comportamento, formas de perceber, ser, pensar e agir, gerando constantes transformações tanto em si quanto no objeto de aprendizagem, não sendo esta restrita ao ato de memorizar e sim à construção do conhecimento de cada um e da coletividade. $\mathrm{O}$ ato de aprender é construído através de experiências vividas dependendo do grau de satisfação que esta proporcionará. Portanto, é uma necessidade de caráter universal, contribuindo para o desenvolvimento das características psicológicas, que se inicia no seio familiar e se estende por toda vida, desde a idade mais tenra, nas trocas que faz com a mãe, a criança cega já está realizando aprendizagens, ao mesmo tempo em que vai construindo um estilo próprio de aprender, modificando - o e ampliando - o na medida em que outras interações vão acontecendo. 
(...) A aprendizagem é uma atividade contínua, iniciando - se nos primeiros minutos da vida e estendendo - se ao longo dela. Isto significa expandir o conceito de aprendizagem: ele não deve estar restrito ao período escolar e pode ocorrer tanto na infância quanto na vida adulta. A escola será um - entre muitos - dos ambientes em que será possível adquirir conhecimento. Para tanto, ela terá que incorporar os mais recentes resultados das pesquisas sobre aprendizagem e assumir a função de propiciar oportunidades para o aluno gerar e não somente consumir conhecimento, desenvolvendo assim, competências e habilidades para poder continuar a aprender ao longo da vida. (Valente, 1998).

Percebe-se que, sob esta ótica, a aprendizagem nem sempre é sistematizada, seqüenciada e compartimentada como se apresenta nos currículos escolares, em alguns momentos, o aprendiz resolve as situações com facilidade; em outros, surge a dificuldade que $o$ mobiliza para a solução. Sendo assim, aprender implica em dificuldade de aprender e a nãoaprendizagem pode representar, em muitos casos como sentido de exclusão, portanto, assegurar a igualdade de oportunidades e participação com qualidade, continuidade e aprendizado, respeitando-se as individualidades, permitindo a construção da identidade pessoal, a futura integração e participação na sociedade, que tem como papel principal o dispertar de um pensamento inovador e inclusivo, contando dessa forma com auxílio de ferramentas tecnológicas disponíveis no mundo digital.

\section{A TECNOLOGIA EDUCACIONAL A SERVIÇO DA PESSOA COM ESPECIFICIDADE VISUAL}

Os recursos tecnológicos são de fundamental importância para a inclusão de pessoas cegas na sociedade, normalmente esses recursos são utilizados nos centros e nas escolas que atendem a esses alunos, com o auxílio de professores com especialização na área, desde que, o aluno seja considerado integrante da turma regular, devendo participar de todas as atividades presentes em classes. Os recursos de apoio são: a bengala, o assinador, a reglete, o sorobã, a máquina Braile, os livros didáticos adaptados, impressora Braille e a máquina de Termofor.

$\mathrm{O}$ avanço tecnológico tem tido abrangência em todos os setores, verificando-se sua influência na política, economia, cultura e educação em nível mundial. Esse fato tornou-se real quanto às condições de possibilitar mais acessibilidade às pessoas cegas, pois a evolução tecnológica vem sendo de grande relevância para efetivar a participação destas pessoas na sociedade. (Machado, 2003).

As pessoas com especificidade visual tem várias ferramentas que podem auxiliar no seu dia a dia, nos estudos e no lazer. Todos os anos surgem novidades tecnológicas nessa área, 
infelizmente essas novidades nem sempre estão acessíveis à maioria dos cegos pelo seu alto custo, muitos desses produtos são importados e caros.

Além de contar com os diversos programas para computadores disponíveis no mercado, os cegos passam a navegar na Internet, já existe um movimento internacional no sentido de tornar as páginas de Internet cada vez mais acessíveis seguindo algumas regras simples de diagramação, qualquer página de Internet pode ser lida pelos programas leitores de tela, com isso, um novo mundo de informações estão disponíveis e a serviço.

\section{CONSIDERAÇÕES FINAIS}

Falar em educação, inclusão e tecnologia, nos da à visão que as pessoas com especificidade visual trazem consigo um histórico de exclusão da sociedade, o que se constitui em problema social grave, não é incomum, nos depararmos com tais pessoas empurradas à mendicância ou subvida por não encontrarem oportunidades de aprendizagem nas escolas ou no trabalho, a educação escolar mostra alguns obstáculos que podem dificultar o processo de aprendizagem dos alunos cegos, como: As dificuldades de identificação; concepção de que a especificidade ocasiona; a falta de acesso ou adaptação de conteúdos didático-pedagógicos informatizados; a ausência de acessibilidade arquitetônica; a inexistência de recursos de tecnologias e o não reconhecimento das potencialidades destes alunos.

No decorrer deste estudo percebemos grandes avanços na tecnologia educacional, onde foram desenvolvidos diversos equipamentos para serem acoplados aos computadores, visando adaptar uma pessoa com especificidade visual ao seu uso, infelizmente sem muitos resultados. Atualmente com o desenvolvimento da informática e a existência de leitores de telas, dezenas de pessoas passaram a manipular essas máquinas, auxiliados por uma visão tecnológica conhecida como multimídia.

Os conhecimentos dos diversos recursos tecnológicos disponíveis hoje favorecem a metodologia de ensino e aprendizagem das pessoas com especificidade visual, além de garantir a acessibilidade educacional, que é imprescindível no decorrer de seu processo de escolarização. Dessa forma, competem aos educadores, gestores e de mais profissionais de instituições escolares, prepararem ambientes, que atendam as verdadeiras necessidades desses alunos, com a criação de estratégias tecnológicas que levem o acesso aos computadores, adaptados, com os diversos softwares existentes no mundo virtual, facilitando a condição e a participação do desenvolvimento de sua aprendizagem no campo profissional. 


\section{REFERÊNCIAS BIBLIOGRÁFICAS}

BORGES, J.A, Paixão, B. e Borges, S.

- Projeto DEDINHO - DOSVOX -

Uma nova realidade educacional para

Deficientes Visuais - Rio de Janeiro -

2002. Disponível em:

http://intervox.nce.ufrj.br/dosvox/texto

s/artfoz.doc. Acesso em: 15 jun. 2011.

BRAILLE, Louis. Citação.

ELISABETH FERREIRA DE JESUS é professora e coordenadora do Programa Educacional Alternativo - PREA- do Instituto Benjamin Constant. http://intervox.nce.ufrj.br/dosvox/

Acesso 22/07/2011.

GALVÃO, T. A. F.; DAMASCENO, L. L.- As Tecnologias da Informação e da Comunicação como Tecnologia Assistiva, Brasília, PROINFO/MEC, 2000.

JESUS, Elisabeth Ferreira. Atividade de Vida Diária. Apostila. Rio de Janeiro. 1994.
LA TAILlE, Ives. Piaget, Vigotsky $e$ Wallon: Teorias psicogenéticas em discussão. São Paulo: Summus, 1992.

MACHADO, 2003. Citação.

OLIVEIRA, Ramon de - "Informática Educativa" - Dos planos e discurso à sala de aula. Editora Papirus - $7^{\text {a }}$ edição - Campinas - SP (Coleção Magistério: Formação e trabalho pedagógico), 2002.

ROUCEK, Joseph. - "A Criança Excepcional (Coletânea de Estudos)". IBRASA - vol: 30,

VALENTE, J. A. (1998) Por que o computador na educação. In: VALENTE, J. A. (Org.). Computadores e Conhecimento: Repensando a Educação. $2{ }^{a}$ edição. Campinas, SP: UNICAMP/NIED.

VISCA, Jorge. Clínica Psicopedagógica. Epistemologia Convergente. Porto Alegre, Artes Médicas, 1987.

VALES, E. M. A Tecnologia Assistiva na Especificidade Visual.Complexitas - Rev. Fil. Tem. Belém, v. $4, \quad$ n. $2, \quad$ p. 27-32 jul./dec. 2019. Disponível em: http://www.periodicos.ufpa.br/index.php/complexitas/article/view/8052>. Acesso em: 30 de janeiro de 2020. 